\title{
Comparative analysis of seepage simulation for embankment in cold area during ice flood season and non-ice flood season
}

\author{
CHEN Mo ${ }^{1,2}$, DAI Changlei ${ }^{1,2}$, LI Yang ${ }^{1,2}$ \\ ${ }^{1}$ Institute of Groundwater in Cold Region, Heilongjiang University, Harbin, 150080 China \\ ${ }^{2}$ School of Hydraulic and Electric Power, Heilongjiang University,Harbin,150080 China
}

\begin{abstract}
Influenced by meteorological and environmental factors, ice flood is easy to occur in cold areas, causing the flood level to rise substantially and threatening the safety of embankments. Based on the analysis of the influencing factors of the seepage of the dike in the cold region, the seepage simulation model of the dike is constructed and solved by the SEEP/W module of Geo-studio software. The seepage of the Dike Section in the ice flood season and non-ice flood season under the scenario of 100-year flood level is compared and analyzed. The results show that, (1) The seepage path of non-ice flood dike mainly passes through the base layer of the dike, and the seepage path of the dike is affected by the frozen shell during the ice flood season, and the seepage path of the dike mainly passes through the frozen shell. (2) The maximum velocity of Dike Seepage in the season of ice flood is higher than that in non-ice flood season, which is easy to cause piping and collapse. (3) the maximum gradient of the embankment during the flood season has also increased, exceeding the allowable slope value of the project. During the season of ice flood, the embankment is unstable, and the embankment protection should be strengthened during the flood season.
\end{abstract}

\section{Introduction}

Influenced by many factors, such as rainfall, climate, environment and river location, ice flood is easy to occur in cold regions, which threatens the safety of embankments (Wei et al. 2015). In the following cases, the flood level will be greatly raised during the ice flood season. First, it usually occurs in the freezing season when the temperature changes from zero to zero. Because of the long freezing season, the duration of the flood will continue to increase correspondingly, which makes the water level rise sharply and does great harm to the coastal water conservancy projects. Secondly, the ice bank flood usually occurs during the freezing period, because the formation of the ice bank is very rapid, making the upstream water level in a short period of time quickly raised, along the break of the embankment, flood occurred immediately, the safety of nearby buildings and peripheral facilities have a greater destructive effect; thirdly, the ice pressure flood, a large number of ice blocks accumulated. Together, the effect of scour on buildings (Chen et al. 2011).

In recent years, a number of scientists have done a lot of research on seepage in embankments. Fusao Oka et al. (2010) established a numerical model of unsaturated soil, based on mixing theory and elastic-viscoplastic constitutive model. The gas-soil-water coupling finite element method considering unsaturated seepage was used to analyze the multi-phase deformation of river embankment. Barbetta S et al. (2017) effectively reduces the probability of the occurrence risk of fragile embankments by studying the influence of hydraulic parameters on the accurate description of seepage parameters. Cen Weijun et al. (2016) used the water-gas two-phase unsaturated seepage model to analyze the saturated-unsaturated seepage of embankment under the coupling condition of rainfall infiltration and water level change in front of embankment [5]. Zhang Yu (2013) established a porous media model by useing the finite volume method of fluent numerical simulation software, the dike seepage field and the anti-seepage wall with antiseepage measures were analyzed and studied [6]. However, due to the influence of environment and geographical location, there is little research on levees in cold areas under the background of ice flood at home and abroad.

In this study, the seepage environment of dike engineering in cold region during ice flood season and non-ice flood season is analyzed, the typical dike section parameters in different periods are set up, and the mathematical model of dike seepage simulation is constructed. The seepage of dike engineering in cold region during ice flood season and non-ice flood season is analyzed under different scenarios of water level. The comparative analysis of the flow characteristics provides scientific support for flood control and safety in the cold

\footnotetext{
* Corresponding author: Chen Mo chenmocc12@163.com
} 
area of the flood season.

\section{Methods and materials}

\subsection{Typical section of embankment}

Taking a certain section of the river in the cold region as the study area, there are frequent floods in the region, mainly forming three types of floods. One is the floods caused by summer rainstorms, which usually occur between June and August. The other is the floods caused by the combination of snow melting and rainfall in spring. The third is ice flood. During the ice flood period, the second and third forms of floods have a great impact on the safety of embankments. This paper selects the typical embankment section at the corner of the river from the rapid to slow down as the research object. This section has occurred many dangerous situations in history, especially in 2013, a serious break accident occurred.

After the dam break, the embankment engineering is reinforced to increase the thickness of both sides of the embankment and strengthen the anti-seepage ability. The width of the top of the embankment was extended to 8 meters, and the slope with upriver and backwater was gentler than the original slope, and was reset to $1: 4.0$. If the upstream slope of the sand dike is slower than 1:4.0, keep its original slope ratio, which is steeper than 1:4.0, all of them are cut to 1:4.0, and the backwater slope ratio is 1:4.0. The design of the mixed dike slope is the same as that of the sand dike. If the height of the dike exceeds 6 meters, a 2.0 meters wide platform is set at 3 meters from the top of the dike (Zhang et al. 2017).

The schematic diagram of the typical section is shown in Figure 1.

According to the different time and type of flood, the embankment materials in non-ice flood season and ice flood season are divided, as shown in Figure 2 and Figure 3. The levee in cold area is divided into three areas: sandy soil area, low liquid limit clay area and poor gradation medium sand area. Detailed parameters are shown in Table 1. The levee in cold area is divided into nine areas of three materials during ice flood season. The zones of the same material are affected by freezing and thawing. The permeability coefficient is different. Detailed parameters can be found in Table 1 and Table 2.

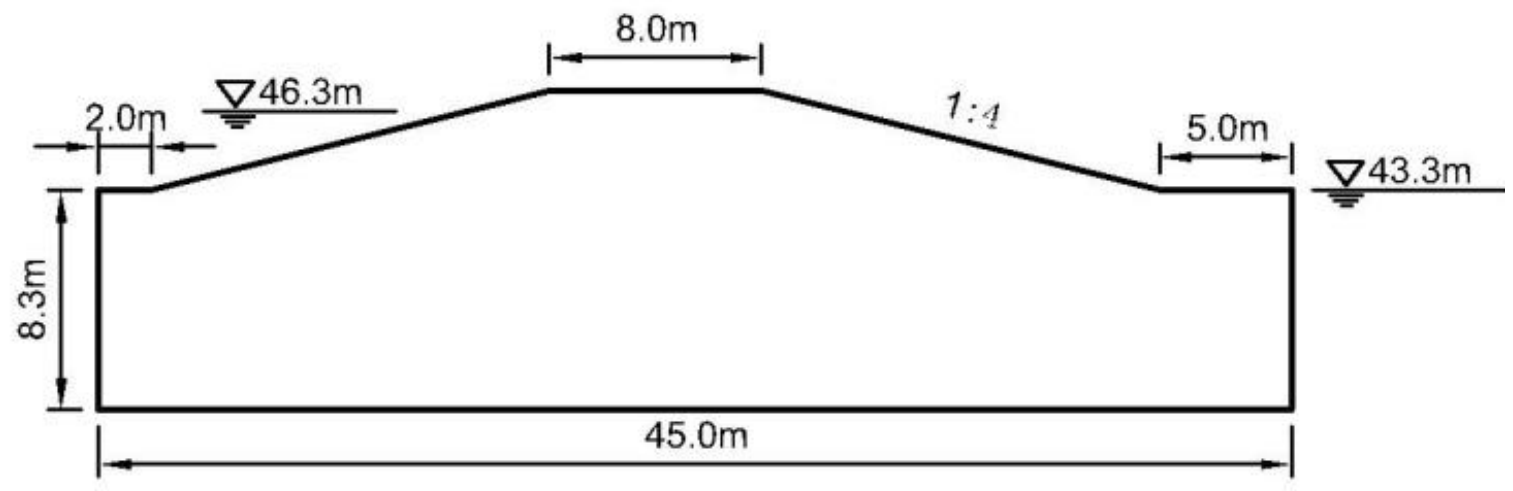

Fig. 1 Schematic diagram of typical section of embankment

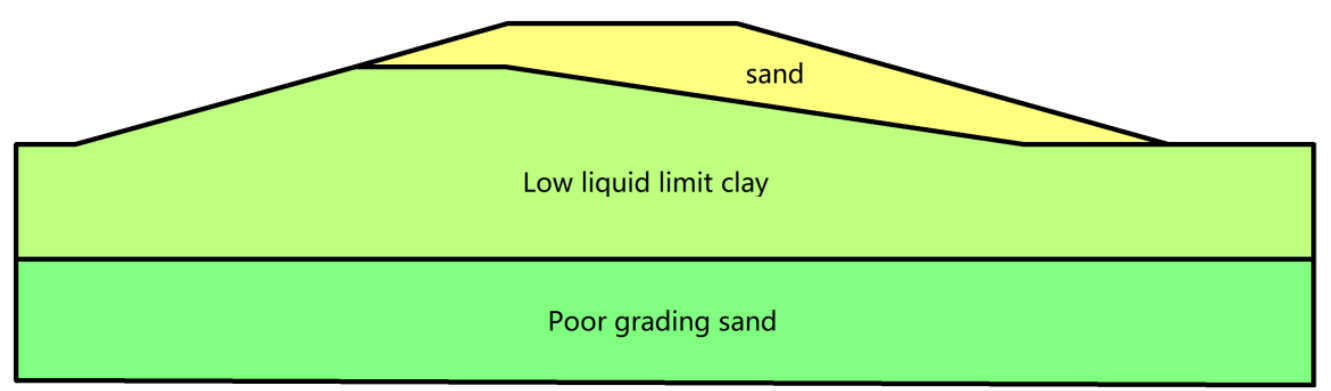

Fig. 2 Material profile of typical section of embankment during non-flood season

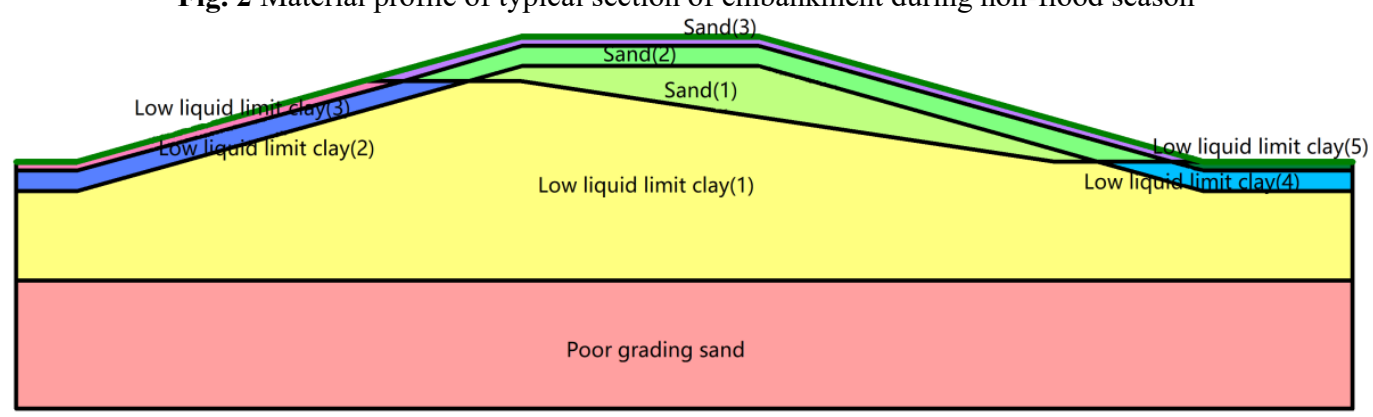

Fig. 3 Material profile of typical section of embankment during flood season 


\subsection{Methods and steps}

In this study, the numerical simulation method is used to establish the mathematical model of typical cross-section seepage simulation, and the SEEP / W module of Geostudio software is used to solve it.

\subsubsection{Seepage simulation model}

The governing equation of two-dimensional seepage is (Chen et al. 2015; Lou et al. 2008):

$$
\frac{\partial}{\partial \chi}\left(k_{\chi} \frac{\partial h}{\partial \chi}\right)+\frac{\partial}{\partial}\left(k_{Z} \frac{\partial h}{\partial Z}\right)=C \frac{\partial h}{\partial t}
$$

The conditions for solution are as follows.

1) initial conditions:

$$
\left.h\right|_{t=0}=h_{0}(h, z, 0)
$$

2) boundary conditions: assumed boundary $\Gamma=\Gamma_{1}+\Gamma_{2}$

$$
\begin{aligned}
& \left.h\right|_{t=0}=h_{0}(h, z, t) \\
& -k_{n} \frac{\partial h}{\partial n} \mid \Gamma_{2}=q \circ
\end{aligned}
$$

\subsubsection{Calculation steps of seepage simulation based on Geo-studio}

1. Building geometric models

According to the actual situation, the geometric shape of the research section is drawn according to a certain proportion, the rectangular coordinate system is established with the bottom edge as the $\mathrm{X}$ axis and the left boundary as the $\mathrm{Y}$ axis, and the geometric model of the research section is established. At the same time, SEEP / $\mathrm{W}$ also supports the DXF format of CAD, so it is possible to import the embankment diagram after removing the filling and saving it into DXF format.

\section{Mesh generation}

GeoStudio's mesh is generated automatically, and the hybrid mesh is the characteristic of its mesh type, that is, there are both quadrilateral and triangular mesh settings, and both of them can exist simultaneously (Chen et al. 2009). Mixed cell settings can be very good to make the boundary fit, this time the use of quadrilateral settings and triangle settings. In this work, the mesh is divided according to the global element approximate size. The mesh is divided as shown in Fig. 4 and Fig. 5.

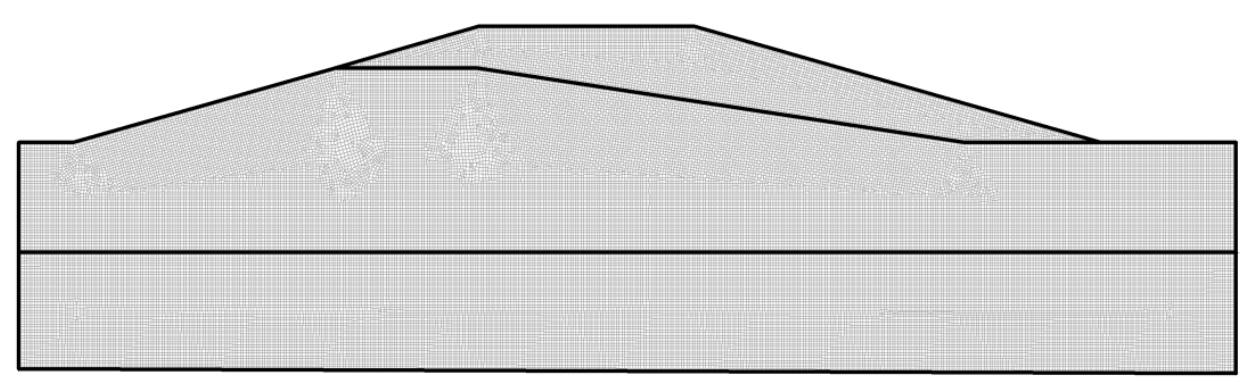

Fig. 4 Mesh section of typical section of embankment during non-flood season

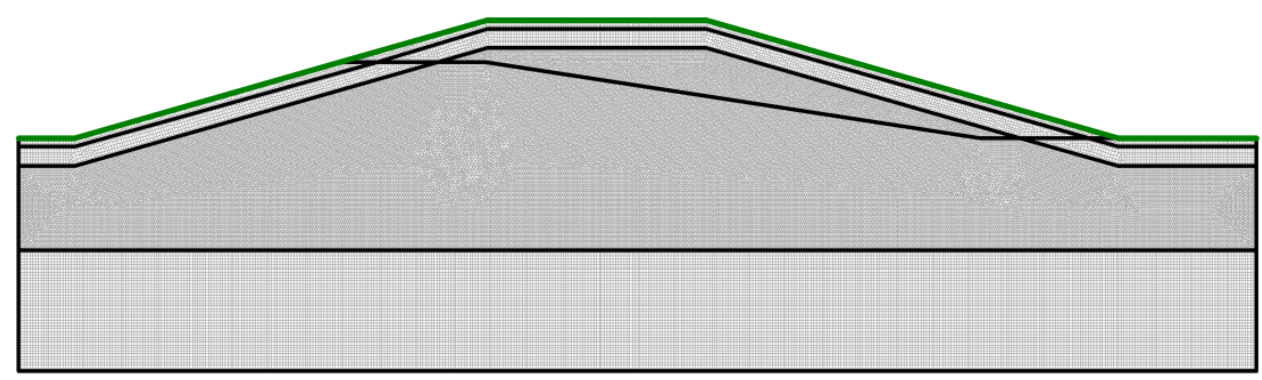

Fig. 5 Mesh section of typical section of embankment during flood season

The global cell size of non-ice season section is $0.1 \mathrm{~m}$, 93525 nodes, 46786 cells. The global cell size $0.1 \mathrm{~m}$, 50968 nodes and 76970 cells in ice season (Moellmann A et al. 2011; CHO S E, 2012).

3. Define material properties

According to the data collection and test results, the permeability coefficients and other parameters of the materials in each section can be determined, and some parameters can be estimated according to the expert experience values. According to the research needs, the permeability coefficient and other parameters of each region of the cross section were defined in SEEP/W.

The typical section of this simulation is the mixed material dike. The permeability coefficient of the dike material in non-ice flood and ice flood season is shown in Table 1 and Table 2.

Table 1 Coefficient of permeability for non-flood season 


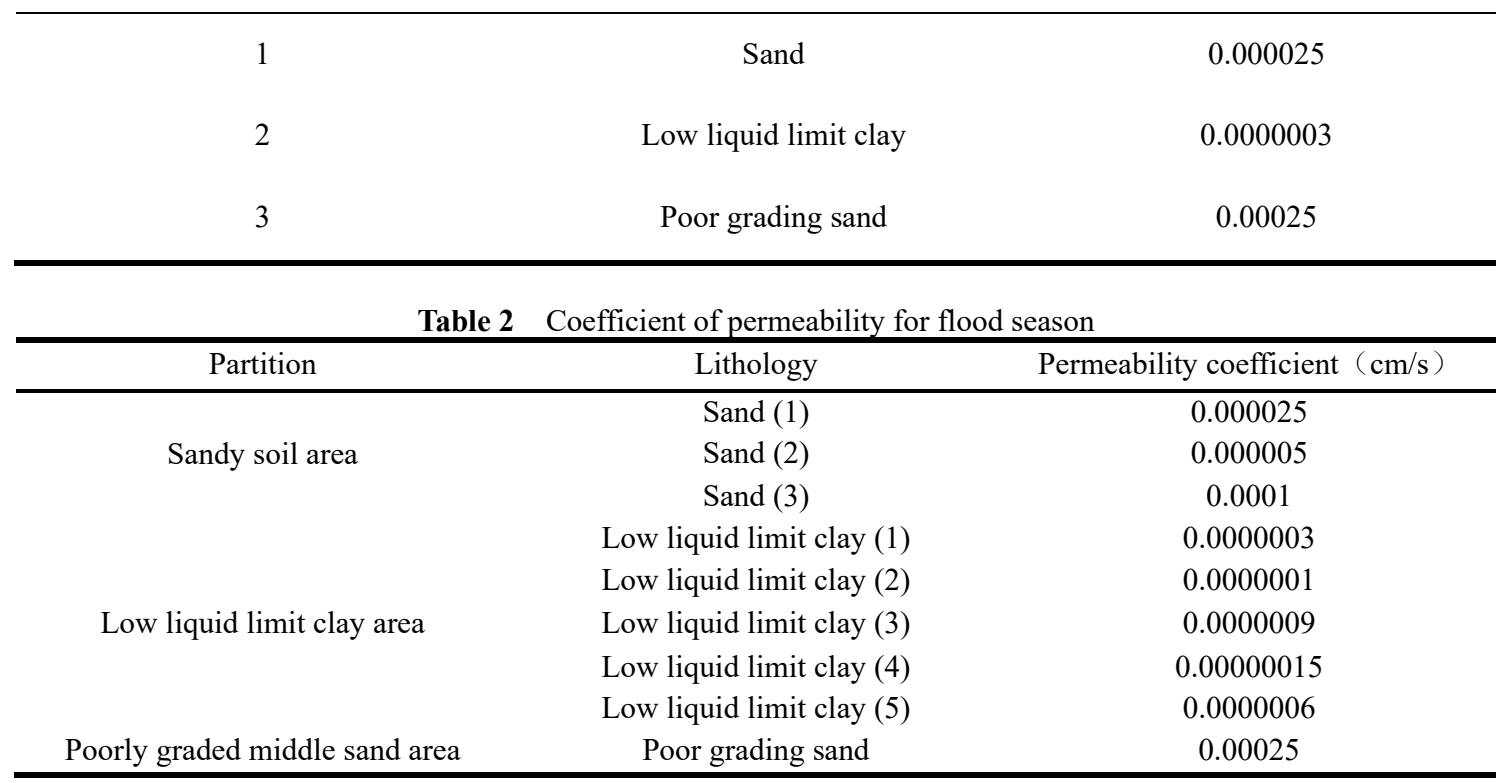

During the freezing season in cold regions, the permeability coefficient of the top layer of the dike will increase with the temperature changing repeatedly from zero to zero, while the material inside the dike has a part of the distance from the surface has not been thawed, there will be a layer of frozen shell, the permeability coefficient of this part of the material is relatively small. The thickness of the frozen shell is $0.7 \mathrm{~m}$, which is $0.3 \mathrm{~m}$ above the surface of the embankment.

4. boundary conditions

The main type of boundary condition is constant head boundary ( $\mathrm{Li}$ et al. 2009). The head value on the left side of the levee is set according to the regional flood scenario. The design standard of the levee in this area is once in 50 years. For the sake of safety, the selected water level is once in a hundred years to simulate the seepage. It is set to $46.3 \mathrm{~m}$, and the right side of the embankment is $43.3 \mathrm{~m}$ (Chen et al. 2016) on the side of the back water side.

5. result output

According to the actual situation of the embankment, the seepage flow at the section where the discharge is set can be obtained, and the velocity vector arrow can be displayed directly. At the same time, the cloud diagrams of various parameters can be drawn, such as total head, pore pressure, pressure head, velocity and gradient.

\section{Results and discussion}

\subsection{Seepage simulation analysis of typical section in non-flood season}

On the basis of the mathematical model of seepage simulation, the seepage pressure line diagram, vector analysis diagram, seepage path diagram, pore water pressure diagram, flow velocity nephogram and slope gradient nephogram of typical Dike Section in non-ice flood season are obtained by using Geo-studio seepage module, as shown in Figure 6-11.

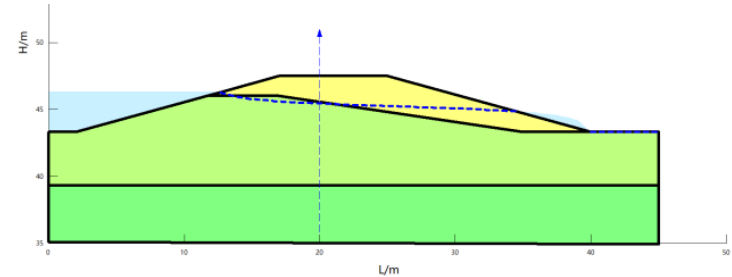

Fig.6 Seepage pressure diagram of typical section in non-flood

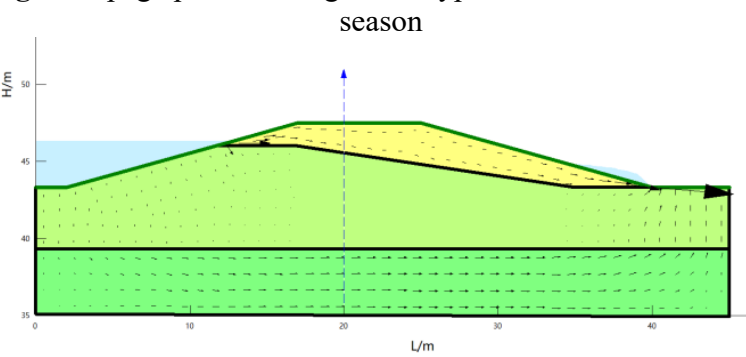

Fig. 7 Seepage vector analysis diagram of typical section in non-flood season

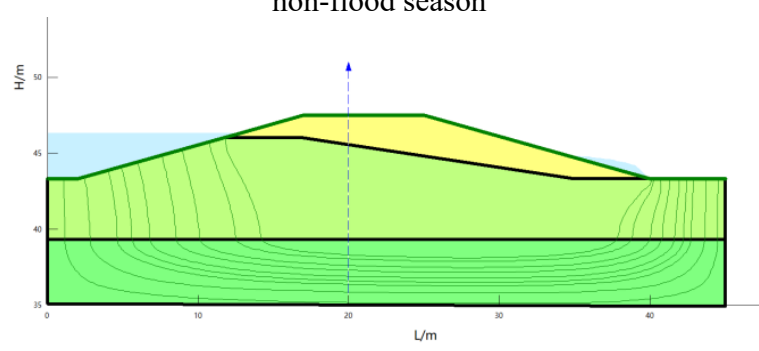

Fig. 8 Seepage path map of typical section in non-flood season

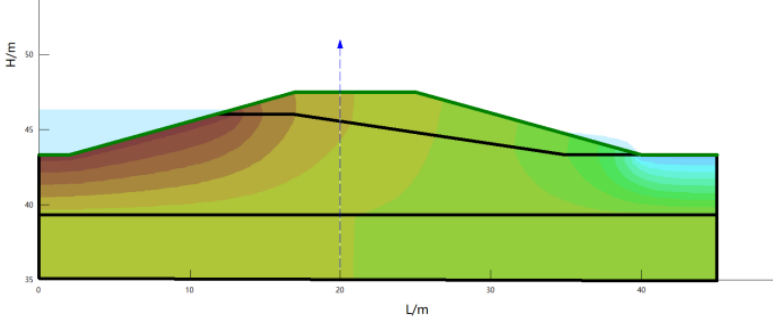

Fig. 9 Seepage pore water pressure diagram of typical section in non-flood season 


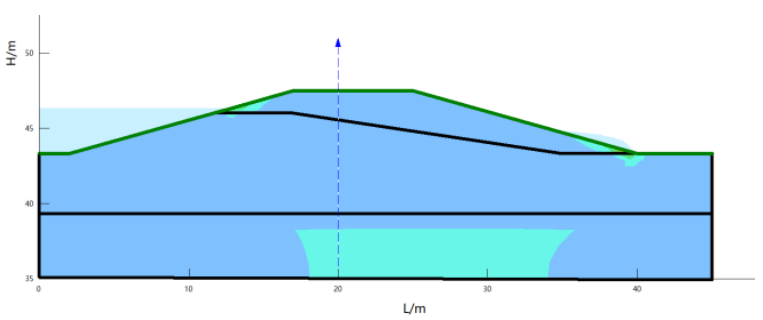

Fig. 10 Seepage velocity cloud map of typical section in nonflood season

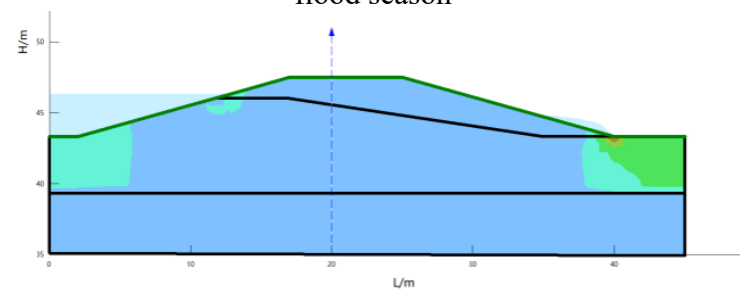

Fig. 11 Seepage gradient cloud map of typical section in nonflood season

Fig. 6 shows that the pressure line enters from upstream, through sandy soil area, rapidly enters low liquid limit clay area, enters sandy soil area in the middle of dam body, exits the dam body at a distance from downstream slope foot, enters at the foot of dam, and finally flows out along the downstream dike surface. It can be seen that the water pressure near the foot of the downstream slope increases, so in the case of a hundred years of floods, it is best to set up protective measures here to ensure the safety of the embankment.

As shown in Fig. 7, the flow direction is from upstream to downstream of the levee, and from the low liquid limit clay area to the middle sand area with poor gradation, and then to downstream horizontally in the middle sand area with poor gradation, and finally to the low liquid limit clay and out of the levee. In the low liquid limit clay area, the flow rate is small because of its low permeability coefficient. But the poor permeability in the middle sand area with poor gradation results in larger flow rate. Another part of the sand flows from the upper part of the embankment and flows out downstream of the embankment. The two part is the flow of water at the downstream dike.

As can be seen from Figure 8, the seepage path flows vertically from the low liquid limit clay upstream to the medium sand with poor gradation, then flows horizontally and vertically back to the low liquid limit clay and flows out of the dike.

Fig. 9 shows that the change of water head on the left side of the embankment is from rapid to slow, and the change of water head on the right side of the embankment is from slow to rapid, and drops rapidly in a short distance.

It is shown from Fig. 10 that the seepage rate in the dike is relatively small under the condition of once-in-acentury flood level $(46.3 \mathrm{~m})$. In the sandy area, the seepage rate at the upstream interface changes obviously, and the seepage rate in the middle area is almost the same. In the poor sand grading area, the infiltration rate in the middle part is larger than that on both sides. However, the seepage rate of low liquid limit clay at the foot of the embankment has increased, and there is no significant change in other areas. The minimum seepage rate is $0.003 \mathrm{~m} / \mathrm{d}$ and the maximum seepage rate is $1.116 \mathrm{~m} / \mathrm{d}$ at the foot of the downstream dike.

It can be seen from Fig. 11 that the slope ratio of the embankment is relatively small as a whole, and the change of the slope ratio is especially small in the sand region with poor gradation at the bottom of the embankment. In the low liquid limit clay area, the slope gradient on the left side changed slightly, but there was no obvious change in the middle area. The slope gradient on the right side changed greatly, especially at the foot of the lower levee, the maximum value of the slope gradient was 1.12 . The minimum gradient is 0.0005 . The minimum gradient is also the slope value of most of the embankment.

\section{2 seepage simulation analysis of typical section in ice flood season}

Based on the mathematical model of seepage simulation, the seepage pressure line diagram, vector analysis diagram, seepage path diagram, pore water pressure diagram, velocity nephogram and slope nephogram of typical section dike during ice flood season are obtained by using Geo-studio seepage module, as shown in Figure 12-17.

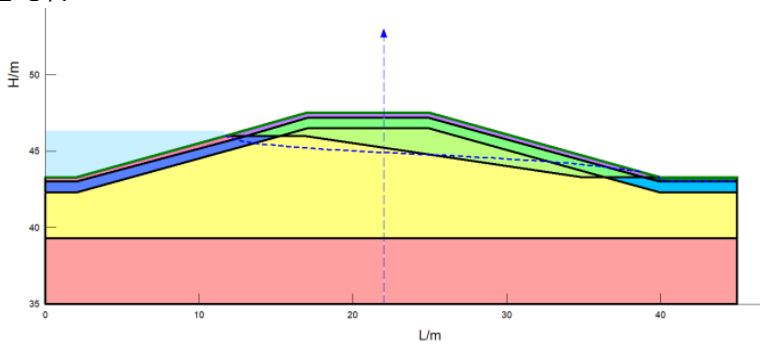

Fig. 12 Seepage pressure diagram of typical section in ice flood

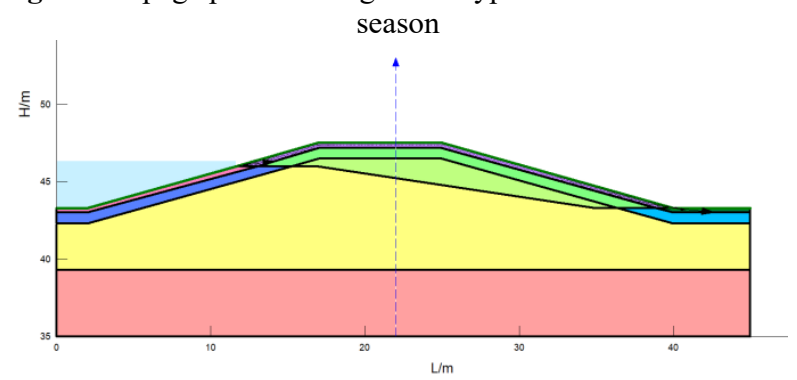

Fig. 13 Seepage vector analysis diagram of typical section in ice flood season

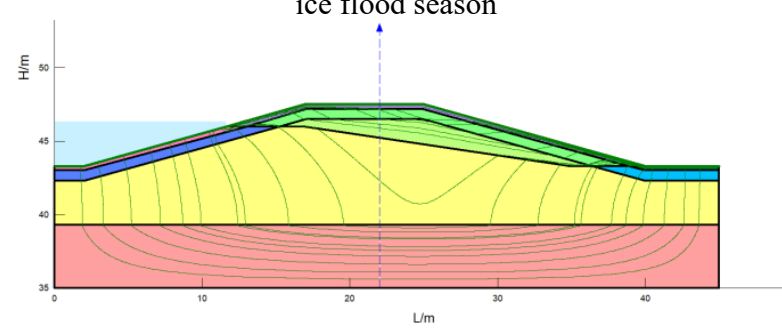

Fig. 14 Seepage path map of typical section in ice flood season

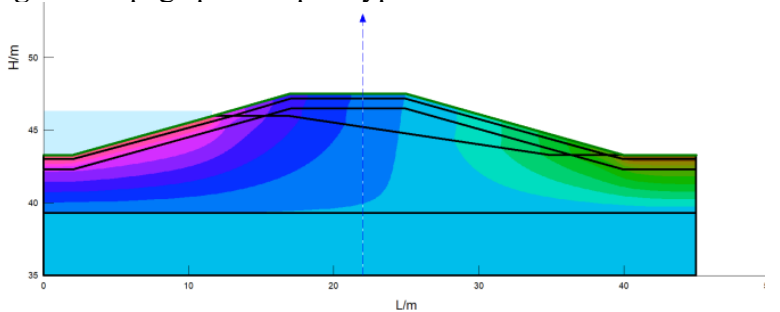

Fig. 15 Seepage pore water pressure diagram of typical section 


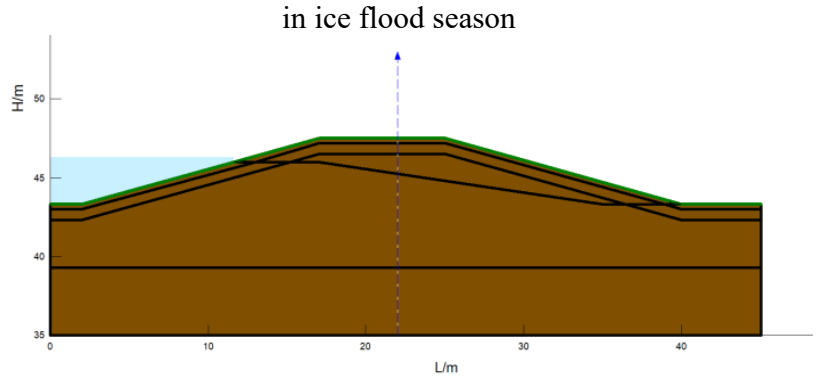

Fig. 16 Seepage velocity cloud map of typical section in ice flood season

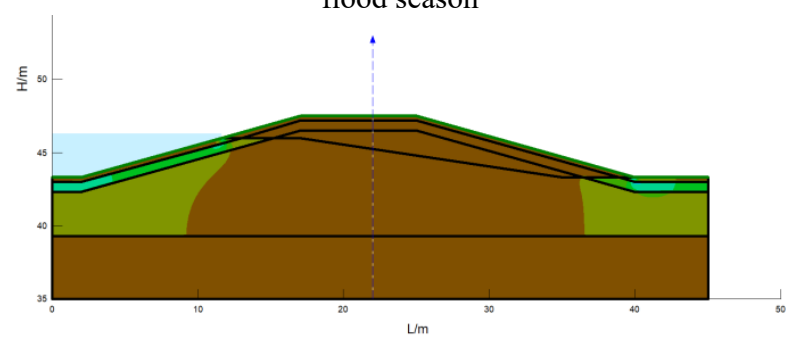

Fig. 17 Seepage gradient cloud map of typical section in ice flood season

From the pressure line diagram of Fig. 12, it can be seen that the pressure line starts from the highest point of water level in the upper reaches of the embankment slope and flows out along the foot of the downstream slope in sequence through low liquid limit clay (3), low liquid limit clay (2), low liquid limit clay (1) and sand (1), sand (2) and sand (3). It flows into the downstream slope and enters the low liquid limit clay (5) area and flows out of the dam body. Due to the large difference of water level in the upstream, the pressure line is relatively steep. At the same time, the phenomenon of overflow will occur between the end of the pressure line and the foot of the dyke.

As shown in Fig. 13, the velocity at the beginning and the end of the flow is higher than that at the middle part, and it runs through all the sand regions. The velocity in the sand region is arranged in sequence as sand (3), sand (1) and sand (2). There is little seepage in the low liquid limit clay area, mainly because the low liquid limit clay permeability coefficient is very small. There is no seepage in the middle sand area with poor gradation.

As can be seen from Fig. 14, the seepage path runs through the whole levee body, part of which flows vertically from the low liquid limit clay upstream to the bad medium sand, then flows horizontally and vertically back to the low liquid limit clay, and flows out from the foot of the lower levee. The other part passes through the sandy soil in the upper part of the dyke, where the seepage path is very dense. It is also verified that the velocity is very large here. The dense degree of seepage path is as follows: sandy soil (3), sandy soil (1) and sandy soil (2).

From Fig. 15, it can be seen that the water head on the left side of the embankment changes from rapid to slow, and the water head on the right side of the embankment changes from slow to rapid, and drops rapidly within a short distance.

According to the velocity nephogram in Fig. 16, the seepage rate of the whole dike is extremely inhomogeneous under the condition of once-in-a-century flood level $(46.3 \mathrm{~m})$. The seepage rate of medium sand with poor gradation is almost 0 . The upper layer velocity of the low liquid limit clay region is very small. The minimum value of the whole region is $0.00005 \mathrm{~m} / \mathrm{d}$, and the velocity of the sand region is higher than that of the other two regions. The maximum seepage velocity is $14.36 \mathrm{~m} / \mathrm{d}$ in the sand (3) area, which occurs not far from the foot of the slope. The flow velocity of upstream surface and embankment is slightly smaller than the maximum value.

The minimum slope gradient is 0.0000054 , and the minimum slope gradient is also the slope gradient in most areas of the embankment. The slope gradient of the whole area of the poor graded medium sand is very small, and the slope gradient of the low liquid limit clay area of the dike is slightly higher than that of the middle. The gradient of the slope gradient in the frozen crust varies greatly, and the gradient of the slope gradient at the upper water surface and the boundary of the dike varies greatly. The stability of the embankment will not be greatly affected. The maximum slope gradient appears at the foot of the lower levee due to the ice flood. Usually, the method to judge whether the seepage failure occurs at the foot of the levee is to determine whether the slope reaches the adjacent slope according to the levee engineering specifications. According to the relevant engineering specifications, the near slope gradient ratio 2 is selected, and the maximum value is 2.17 through seepage simulation, which is larger than the critical slope gradient when seepage failure occurs.

The characteristic parameters of seepage simulation results of typical sections of embankments in cold regions during ice flood season and non-ice flood season are statistically compared, and the results are shown in Table 3 .

\begin{tabular}{ccccc}
\hline $\begin{array}{c}\text { Characteristic } \\
\text { parameters }\end{array}$ & $\begin{array}{c}\text { Water level } \\
(\mathrm{m})\end{array}$ & $\begin{array}{c}\text { Maximum flow } \\
\text { rate }(\mathrm{m} / \mathrm{d})\end{array}$ & $\begin{array}{c}\text { Maximum } \\
\text { slope }\end{array}$ & $\begin{array}{c}\text { Allowable } \\
\text { maximum gradient }\end{array}$ \\
\hline Non-flood season & 46.3 & 1.116 & 1.12 & 2 \\
Flood season & 46.3 & 14.36 & 2.17 & \\
\hline
\end{tabular}

It can be concluded that, under the same flood level, the maximum velocity of seepage and the maximum slope gradient of typical section of embankment in cold region during ice flood season are obviously increased, and the instability of embankment is enhanced. 


\section{Conclusion}

In this study, the seepage of dike engineering in cold region during ice flood season and non-ice flood season is analyzed under different scenarios of water level. The comparative analysis of the flow characteristics provides scientific support for flood control and safety in the cold area of the flood season.

(1) Compared with the seepage path occurring at the base of dike during non-ice flood period, the seepage path of dike changed under the influence of frozen shell during ice flood period, mainly occurring in the sandy soil (3) area above the frozen shell, and the internal permeability coefficient became smaller.

(2) the maximum seepage velocity of typical sections of embankments has changed. The maximum seepage velocity of typical section of the embankment increased from $1.116 \mathrm{~m} / \mathrm{d}$ to $14.36 \mathrm{~m} / \mathrm{d}$. Compared with the non-ice flood season, the seepage velocity will increase during the ice flood season, which is easy to cause the collapse of the embankment and piping.

(3) the maximum gradient of the typical section of the embankment has changed. The maximum slope gradient increases from 1.12 in non-ice flood period to 2.17 in ice flood period, which is larger than the value of adjacent slope gradient and greatly increases the instability of embankment. Therefore, during the ice flood period, the protection measures for embankments should be strengthened.

\section{Acknowledgments}

This work was jointly supported by Basic research fund of Heilongjiang University in Heilongjiang Province (No. RCCX201701), Project HGZL/KY-02 supported by Management Bureau of Sanjiang, Heilongjiang.

\section{References}

1. Barbetta S, Camici S, Bertuccioli P, et al. Levee body seepage: a refinement of an expeditious procedure for fragility curves and vulnerability diagrams' assessment[J]. HYDROLOGY RESEARCH, 2017, 48(3):763-775.

2. Cen Weijun, Li Dengjun, and Haonan. Analysis of seepage and stability of embankment under coupling change of water level induced by continuous heavy rainfall [J]. Journal of Hohai University(Natural Sciences), 2016, 44 (04): 364-369.

3. Chen Liangliang, Shi Kebin, Li Yong.Boundary Point Method for Seepage Analysis of Dam Foundation[J]. International Journal Hydroelectric Energy, 2009,27(01): 88-89.

4. Chen Siyu, Guo Rui, Qin Bo. Causes and Characteristics of Ice Flood in Heilongjiang Province [J]. Heilongjiang Sci Technol Water Conserv, 2011, 39 (01): 198-199.

5. Chen Xiaowei, Lei Peng, Yang Xiaoya. Seepage and stability analysis of embankment based on GeoStudio[J]. Journal of Changsha University of Science and Technology, 2015,12(01): 63-68.

6. Chen Yuyao, Li Shuang, Li Zhijun, et al. Analysis and construction of seepage simulation model for Bacha sections [J]. Heilongjiang Sci Technol Water Conserv, 2016, 2 (07): 32-37.

7. CHO S E. Probabilistic analysis of seepage that considers the spatial variability of permeability for an embankment on soil foundation[J]. Engineering Geology,2012,133 /134( 3) :30-39.

8. Fusao Oka, Sayuri Kimoto, Naoaki Takada, et al. A Seepage-deformation Coupled Analysis of an Unsaturated River Embankment Using A Multiphase Elasto-viscoplastic Theory[J]. SOILS AND FOUNDATIONS, 2010, 50(4):483-494.

9. Li Chenliang, Shen Zhenzhong, Zhanghua Wutagou flood diversion channel test section embankment seepage field analysis and seepage control research [J]. International Journal Hydroelectric Energy, 2009,27 (05): 55-57.

10. Lou Xiaocong, Huang Cheng, Lou Yiqing, et al. Finite element analysis of slope stability under seepage action [J]. International Journal Hydroelectric Energy, 2008 (03): 57-59+24.

11. Moellmann A, Vermeer P A, Huber M. A probabilistic finite element analysis of embankment stability under transient seepage conditions[J]. Georisk Assessment \& Management of Risk for Engineered Systems \& Geohazards,2011,5 ( 2 ) :110-119.

12. Wei Hongyan, Yu Minghui, Li Yitian, et al. Overflow and burst test of silty clay dyke [J]. Advances in Water Science, 2015, 26 (05): 668-675.

13. Zhang Yu. Numerical analysis of seepage field in embankment engineering based on Fluent [D]. Taiyuan University of Technology, 2013.

14. Zhang Xiaohong, Li Yang, Chen Mei, et al. Seepage simulation analysis of levee project [J]. Journal of Heilongjiang Hydraulic Engineering College, 2017, 8 (03): 20-25. 